\title{
MAPPING AND MONITORING WETLANDS USING SENTINEL-2 SATELLITE IMAGERY
}

\author{
G. Kaplan ${ }^{a *}, \mathrm{U}$. Avdan $^{\mathrm{b}}$ \\ ${ }^{a^{*}}$ PhD Candidate - Anadolu University, Earth and Space Research Institute, Eskisehir, Turkey; - kaplangorde@ gmail.com \\ ${ }^{\mathrm{b}}$ Assistant Professor - Anadolu University, Earth and Space Research Institute, Eskisehir, Turkey; - uavdan @ anadolu.edu.tr
}

KEY WORDS: Wetlands; Remote Sensing; Sentinel-2; Classification; NDVI; NDWI.

\begin{abstract}
:
Mapping and monitoring of wetlands as one of the world`s most valuable natural resource has gained importance with the developed of the remote sensing techniques. This paper presents the capabilities of Sentinel-2 successfully launched in June 2015 for mapping and monitoring wetlands. For this purpose, three different approaches were used, pixel-based, object-based and index-based classification. Additional, for more successful extraction of wetlands, a combination of object-based and index-based method was proposed. It was proposed the use of object-based classification for extraction of the wetlands boundaries and the use of Normalized Difference Vegetation Index (NDVI) and Normalized Difference Water Index (NDWI) for classifying the contents within the wetlands boundaries. As a study area in this paper Sakarbasi spring in Eskisehir, Turkey was chosen. The results showed successful mapping and monitoring of wetlands with kappa coefficient of 0.95 .
\end{abstract}

\section{INTRODUCTION}

Wetlands are among the most biologically productive natural ecosystems in the world. A wetland is a land area that is saturated with water, either permanently or seasonally, such that it takes on the characteristics of a distinct ecosystem (Mitsch, 2009). Wetlands play critical parts in maintaining and improving water quality, mitigating floods, reaching aquifers, and providing habitat for fish and wildlife. The complex hydrology of wetlands controls the source, amount, and temporal and spatial distribution of sediment and nutrient movements, and influences the distribution of flora and fauna (Ustin, 2004). The loss of wetlands has gained considerable attention over the past few decades ( $\mathrm{Ji}$, 2007), more than 50\% since 1900 (WWAP, 2003).

Since the first launch of the satellites in the 1970s, the remote sensing has been growing as a science and in every field of study. Remote sensing technology has proven to be a successful in monitoring wetlands and it has been used as a frequent application. Remote sensing techniques are often less costly and time-consuming for large geographic areas compared to conventional field mapping (Czajkowski, Torbick, \& Lawrence, 2007). Firstly, for wetlands monitoring, color infrared aerial photography and, most recently multispectral visible, infrared, and microwave digital imagery obtained from airborne or satellite-borne sensors have been used (Butera, 1983; Jensen \& Christensen, 1986; Melack \& Hess, 2010). Satellite data enables monitoring of wetland changes seasonally and over longer time periods. Different methods and approaches have been used in wetland monitoring.

Wetlands as a transitional between terrestrial and open-water aquatic ecosystems (Mitsch \& Gosselink, 2015), contains open water bodies, vegetation, and mixture. For classifying these different land covers, a number of researches have been made through the years. Most of the studies use different indexes for distinguishing wetlands from other land covers. Landsat data from 1985 to 2009 has been used for mapping changes in wetland ecosystems in northern Virginia using the NDVI (Normalized Difference Vegetation Index) (Kayastha, Thomas, Galbraith, \& Banskota, 2012). Another study (Dong et al., 2014) uses both NDVI and LSWI (Land Surface Water Index) for mapping wetlands in Northwest China. Other indexes as ARVI (Atmospherically Resistant Vegetation Index) (Kaufman \& Tanre, 1992), SARVI (Soil and Atmosphere Resistant Vegetation Index) (Huete, Liu, Batchily, \& Van Leeuwen, 1997), NDWI (Normalized Difference Water Index) (Dvorett, Davis, \& Papes, 2016) in its different forms (Feyisa, Meilby, Fensholt, \& Proud, 2014; Gao, 1996; McFeeters, 1996). Geographical Information Systems (GIS) have also been widely used aside with remote sensed data in monitoring wetlands. Czajkowski et. al (Czajkowski, et al., 2007) used GIS rule-based decision tree algorithm to classify four different wetland types of interest. The expert system has been shown to be effective in depicting wetland types. The GEMI (Global Environment Monitoring Index) (Pinty \& Verstraete, 1992) gives similar information as NDVI and has been used in wetlands monitoring. Another useful index for monitoring vegetation over wetlands is SARVI2 (Soil and Atmosphere Resistant Vegetation Index) (Huete, et al., 1997). As an addition, other data such as LiDAR data (Huang, Peng, Lang, Yeo, \& McCarty, 2014), DEM (Li \& Chen, 2005), and microwave data (Morandeira, Grings, Facchinetti, \& Kandus, 2016; Moser, Schmitt, Wendleder, \& Roth, 2016; White, Brisco, Dabboor, Schmitt, \& Pratt, 2015) have been used for wetlands monitoring.

However, researchers had difficulties using some of the satellite sensors with low spatial resolution for mapping homogeneous coastal wetlands (Ramsey \& Laine, 1997). Zomer et al. (Zomer, Trabucco, \& Ustin, 2009) found that a majority of Landsat pixels were mixtures of several land cover types in various proportion. Civco et al. (Civco, Hurd, Prisloe, \& Gilmore, 2006) had difficulty separating upper salt marsh from upland forest due to the spatial resolution of Landsat ETM.

Sentinel-2A was successfully launched on 23 June 2015, as a part of the European Copernicus program (Sentinel). Sentinel-2 Multispectral Instrument (MSI), is considered to be the followup mission to the SPOT and Landsat instruments, intended to provide continuity of remote sensing products (Malenovský et al., 2012). Sentinel-2 offers satellite images with a resolution of 10 to 60 meters (Drusch et al., 2012). In comparison with the latest Landsat OLI/TIRS, Sentinel-2 has a better spatial

\footnotetext{
* Corresponding author kaplangorde@gmail.com
} 
resolution, better spectral resolution in the near infrared region, three Vegetation Red Edge bands with 20-meter spatial resolution, but does not offer thermal data. Sentinel-2 MSI sensor compared to existing satellite sensors require adjustment to allow extending actual time series (D'Odorico, Gonsamo, Damm, \& Schaepman, 2013). The frequent use of NDVI compared to other vegetation indices affirms the importance of global monitoring of vegetation (Gobron, Pinty, Verstraete, \& Widlowski, 2000). Differences between sensor can vary from $10 \%-15 \%$ for the red and 2\%-3\% for the near infrared (NIR) reflectance, while NDVI values of vegetated surfaces were found varying across instruments up to $4 \%-6 \%$ (Trishchenko, Cihlar, \& Li, 2002). D`Odorico et al. (D'Odorico, et al., 2013) excluded pixels with NDVI value $<0.3$, representing nonvegetative surfaces, and then random points with NDVI values typical for vegetated surfaced were sampled above this threshold.

The Central Anatolian region of Turkey is known for its high number of wetland areas. The climate system of the Earth has affected not only globally but also locally. A study has shown that Turkeys` second biggest lake, Salt Lake (Tuz Golu), has lost more than $70 \%$ of its water surface area from 1987 to 2005 (Ekercin \& Ormeci, 2010). The results from another study from the Central Anatolian region of Turkey, using NDVI and NDWI retrieved from Landsat satellite data, has shown that the Aksehir Lake water area has decreased from $324 \mathrm{~km} 2$ in 1987 to $100 \mathrm{~km} 2$ in 2016 (Gordana KAPLAN, 2016). This part of Turkey is rich with numbers of different vegetation and wildlife (Vakfi, 1989). Understanding wetland changes using remote sensing techniques is critical to planning ecosystem management and sustainable regional development $(\mathrm{Ji}, 2007)$.

In this study, Sentinel-2 satellite data has been used for mapping wetlands. Different remote sensing techniques were used for classifying and separating the wetlands from the other land covers. First, previously mentioned indexes have been retrieved and adjusted to Sentinel-2 data with threshold observation and comparison to other sensors for vegetation and water monitoring. Afterward, unsupervised and supervised classifications have been performed. Finally, an object-based classification with a decision tree model has been developed for monitoring and mapping wetlands. Decision trees have substantial advantages for remote sensing classification problems because of their flexibility, computational efficiency and intuitive simplicity ( $\mathrm{Ji}$, 2007). All of the used techniques were then compared. For the index analysis and the pixel-based classification ERDAS Imagine software was used, while for the object-based classification and the decision tree model, e-Cognition software was used.

\section{STUDY AREA AND METHODS}

\subsection{Study Area}

As a study area in this paper, Sakarbasi wetland located near the village Cifteler in Eskisehir, Turkey has been chosen. Sakarbasi is the spring of one of the largest rivers in Turkeys', Sakarya river. Sakarbasi spring has a drainage area of $4222 \mathrm{~km} 2$ inside the borders of Eskisehir and Afyon province (Güner \& Güner, 2002). It is considered that in this places the water springs from three point. Two of them are cold and one of them is hot water spring. The wildlife in Sakarbasi is wealthy with different types of fish as well as the vegetation types (Ozgur, 2015), (Emiroğlu, 2011) (Figure 1). The water from Sakarbasi springs is being used for drainage of the Cifteler villages' agricultural areas.

\subsection{Methods}

Sentinel-2 data from 31 July 2016 were used in this study for monitoring Sakarbasi wetlands. Sentinel- 2 is an Earth observation satellite by European Space Agency launched on 23 June 2015 (Sentinel-2A) and as part of the Copernicus Programme to perform terrestrial observations in support of services such as forest monitoring, land cover changes detection, and natural disaster management. Sentinel-2 sensor records 13 bands in the visible, near infrared, and short wave infrared part of the spectrum. It has a spatial resolution of $10 \mathrm{~m}, 20 \mathrm{~m}$, and 60 $\mathrm{m}$. The satellite images can be downloaded free from the Copernicus Open Access Hub ( https://scihub.copernicus.eu/ ). The methodology in this study contains three different approaches for mapping and monitoring wetlands. The workflow applied in this study is shown in Figure 2.

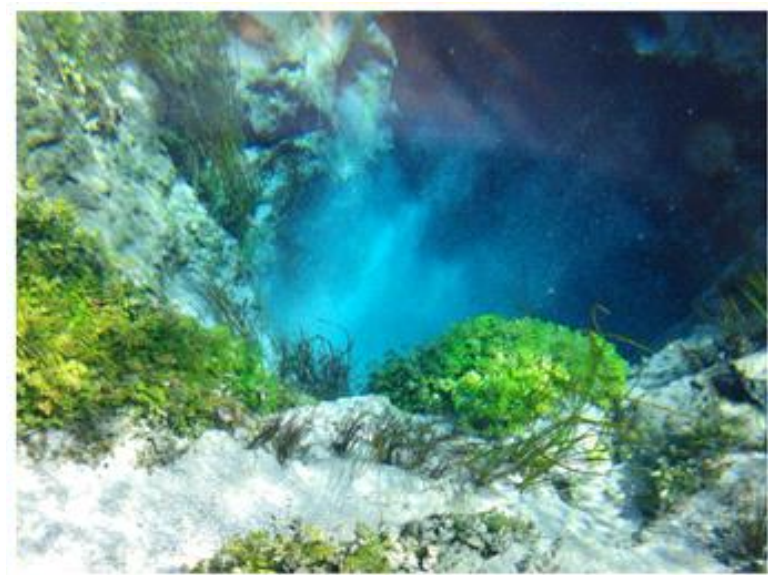

Figure 1. Sakarbasi Springs

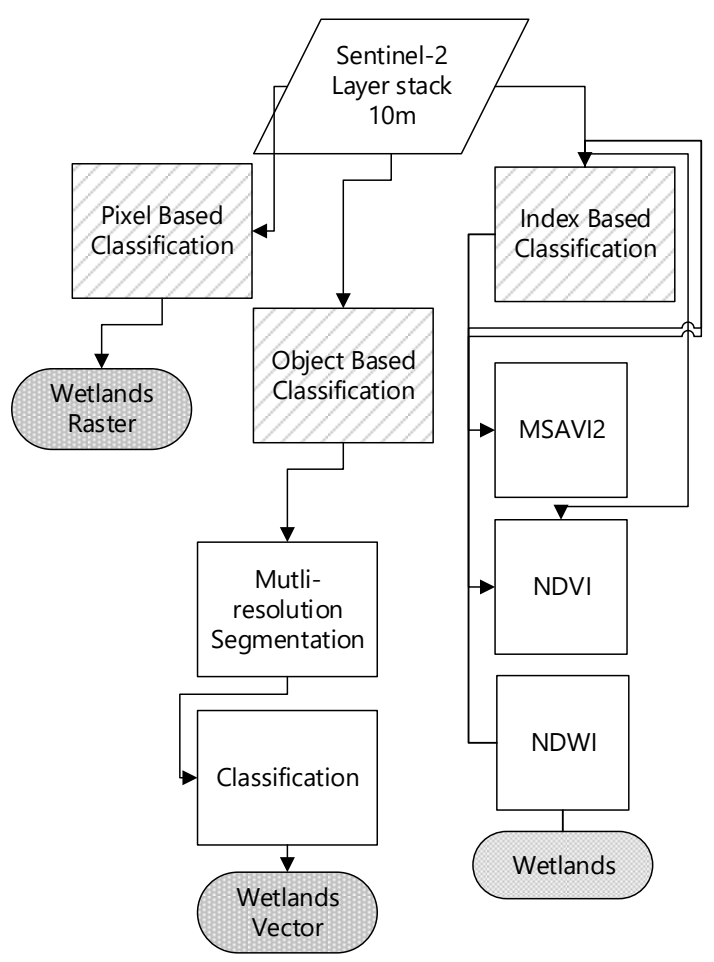

Figure 2. Workflow

The processing of the data contains resampling of the Sentinel-2 bands with $20 \mathrm{~m}$ resolution, to obtain a layer stack of the spectral bands at $10 \mathrm{~m}$. Afterward, pixel-based classification, object- 
based classification and index based classifications were performed.

2.2.1 Pixel based Classification: Supervised and unsupervised classifications were performed for separating the wetlands from the other land covers. For the unsupervised classification, the Sentinel-2 satellite image was classified with twenty different class using the K-means method. In unsupervised classification, pixels are grouped based on the reflectance properties of the pixels and the created groups are called "clusters". The supervised classification needs to be done by selecting representative samples for each land cover class, and the classification is based on the spectral signatures defined by the user. In this case, seven different classes were defined: water, forest, wetlands, urban area, agricultural fields1, agricultural fields2, and green area. The classification was performed with the Maximum Likelihood parametric rule.

2.2.2 Object-based Classification: After processing the Sentinel-2 image, an Object-based classification was performed. Object-based image analysis (OBIA) are frequently used in different study areas as vegetation (Yu et al., 2006), forest covers (Heyman, Gaston, Kimerling, \& Campbell, 2003), water extraction (He, Zhang, \& Hua, 2016) etc. Most of the studies related to OBIA use high-resolution imagery as IKONOS, QuickBird (He, et al., 2016), SPOT (Polychronaki \& Gitas, 2012), while the OBIA studies with medium (Kaplan, 2017) or low resolution are few.

The most important part of the object-based classification is the segmentation where pixels are grouped into objects using an interactive algorithm (Baatz \& SCHÄPE, 2010). The parameters used for multi-resolution segmentation performed in this paper are given in Table 1 .

\begin{tabular}{lc} 
Segmentation Setting & \\
\hline Image Layer weights & $1,1,1,1,1,1,1,1,1,1,1,1,1$ \\
Scale parameter & 30 \\
\hline \multicolumn{2}{l}{ Composition of homogeneity criterion } \\
\hline Shape & 0.6 \\
Compactness & 0.5 \\
\hline
\end{tabular}

Table 1. Mutli-resolution segmentation parameters

After the multiresolution segmentation, all of the objects created within the wetlands were observed as a training data and their spectral characteristics were determined. According to this observation, a tree decision rules were set to the bands that were drastically separating the wetlands objects from the other land cover objects. The tree decision results gave the objects that were possible wetlands. For the missed wetland objects within the already classified wetlands objects were then added to the wetlands class with the condition that their boundaries are $100 \%$ within the previously classified wetlands. The final results were exported as a vector in a shape file.

2.2.3 Index-based Classification: Three different indexes used for wetlands mapping were used in this study, Normalized Difference Vegetation Index (NDVI), Normalized Difference Water Index (NDWI), Modified Soil-adjusted Vegetation Index (MSAVI2). All of the indexes have been used for classifying different land covers within wetlands border Equation 1 -3.

$$
N D V I=\frac{N I R-R}{N I R+R}
$$

$$
M S A V I 2=\frac{2 N I R+1-\sqrt{\left((2 * N I R)^{2}-8(N I R-R)\right)}}{2}
$$

Where NIR represents the near infrared band, $\mathrm{R}$ the red band, and $\mathrm{G}$ is the green band.

All the indexes were calculated for the Sentinel-2 data and the results were compared. New threshold for the NDVI and the NDWI were proposed according to the Sentinel-2 results.

\section{RESULTS}

\subsection{Pixel-based classification}

Digital classification of wetlands from satellite image data is widely used because of the less time consuming and the source data that provide a high temporal resolution (J. R. Jensen, 1996). In this study, both supervised and unsupervised classifications were performed. The results from the classification are presented in Figure 3. The results showed that under unsupervised classification with 20 different classes it was hard to separate wetlands from other dark areas as forest, clouds etc. The supervised classification gave better results successfully extracting the water bodies from the other dark objects. However, it was impossible to separate vegetated areas in the wetland from the open water areas as seen in Figure 3-b.

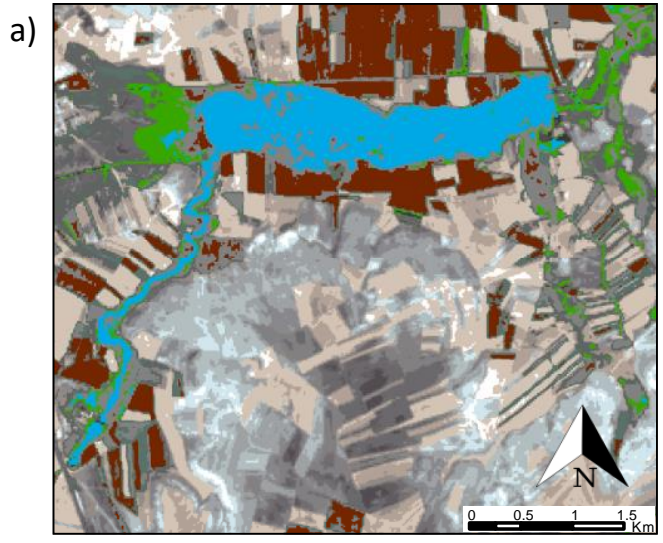

b)

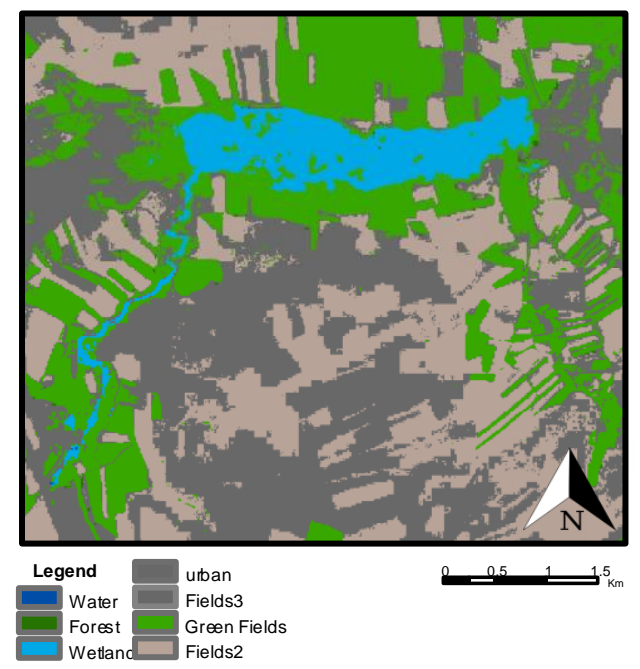

Figure 3. Pixel-based classification results

\subsection{Index-based Classification}

As wetlands are often described as transitional habitats situated between dry land and water bodies (Mitsch \& Gosselink, 2007), 
it can be concluded that they contain vegetation areas, water areas, or dry lands with no direct surface connection to open water (Tiner, Lang, \& Klemas, 2015).

From the results from the NDVI analysis, it was observed that with threshold it is possible to separate the fully vegetated areas from the vegetation and water mixtures. Also, the NDWI index was used for separating the water areas from the other land covers. The NDWI threshold is known to be zero for Landsat images, where higher values from zero represent water pixels, it was observed that the threshold for water areas on a Sentinel-2 satellite image should have a value of -0.15 (Figure $4-c$ ).

As seen in Figure 4a and c, not NDVI nor MSAVI2 could give information related to wetlands, but gave information about the vegetation presents in the wetlands. The mentioned indexes are helpful for monitoring the vegetation density and vegetation changes over time. The NDWI was used for monitoring the open water bodies. In Figure 4-b it can be clearly seen that a threshold of zero (presented with blue) does not extract the small water bodies or the water bodies that contain vegetation. A threshold of -0.15 successfully extracts pixels that contain water, in this case, a mixture of water and vegetation. Although NDVI could give information about vegetation mixtures (Sobrino \& Raissouni, 2000), it is often confused with low vegetated areas (Figure 4-a).

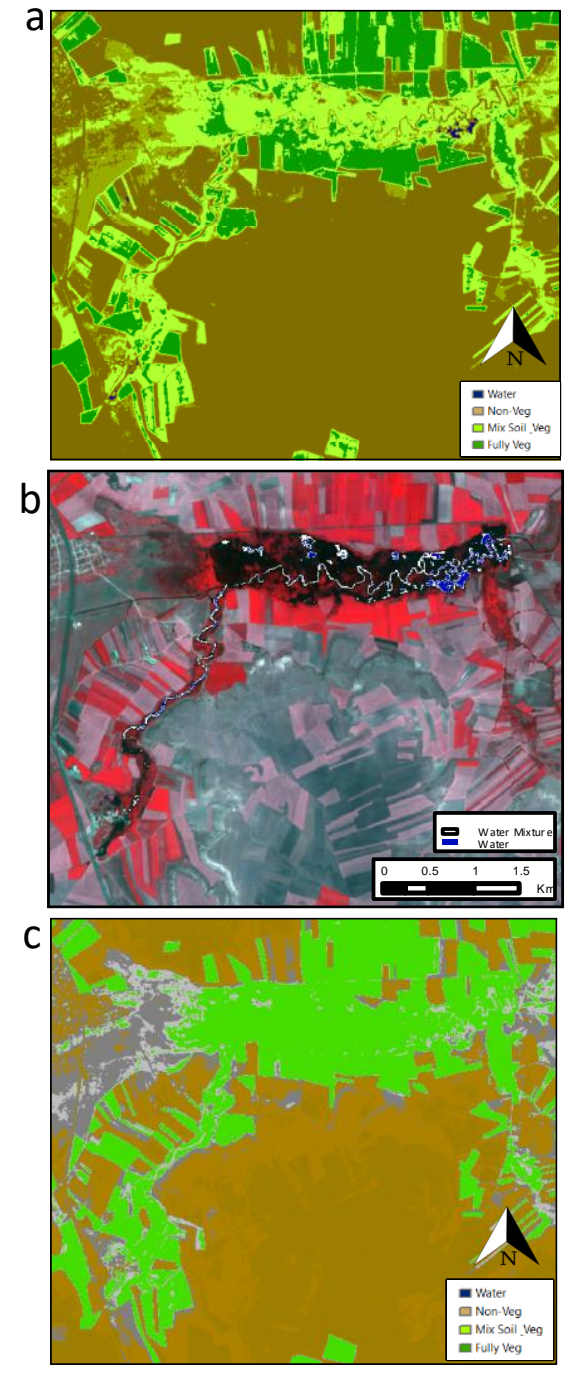

Figure 4. Index based classification; A) NDVI results; B) NDWI results; C) MSAVI2 results.

\subsection{Object-based classification}

The results from the object-based classification showed good results in the boundary extraction section. The training data from the wetland areas helped for classifying other similar objects with the same spectral characteristics. After the multiresolution segmentation, a set of conditions were applied to the classification. It was observed that wetlands areas have near infrared values (B8 - band 8) higher than 900 and lower than 390. The same observation was made for the other bands. It was observed that the biggest mislead could occur from small dark areas, such as parts of forests, but they were eliminated by setting the area condition. The exported results in a vector file overlapped with the wetlands boundaries observed from highresolution imagery (Figure 5-c).

Using the object-based classification, we were able to detect all of the wetlands within the Sentinel-2 frame. The results were then compared with high-resolution images and it was concluded that the only mislead came from clouds shadows.

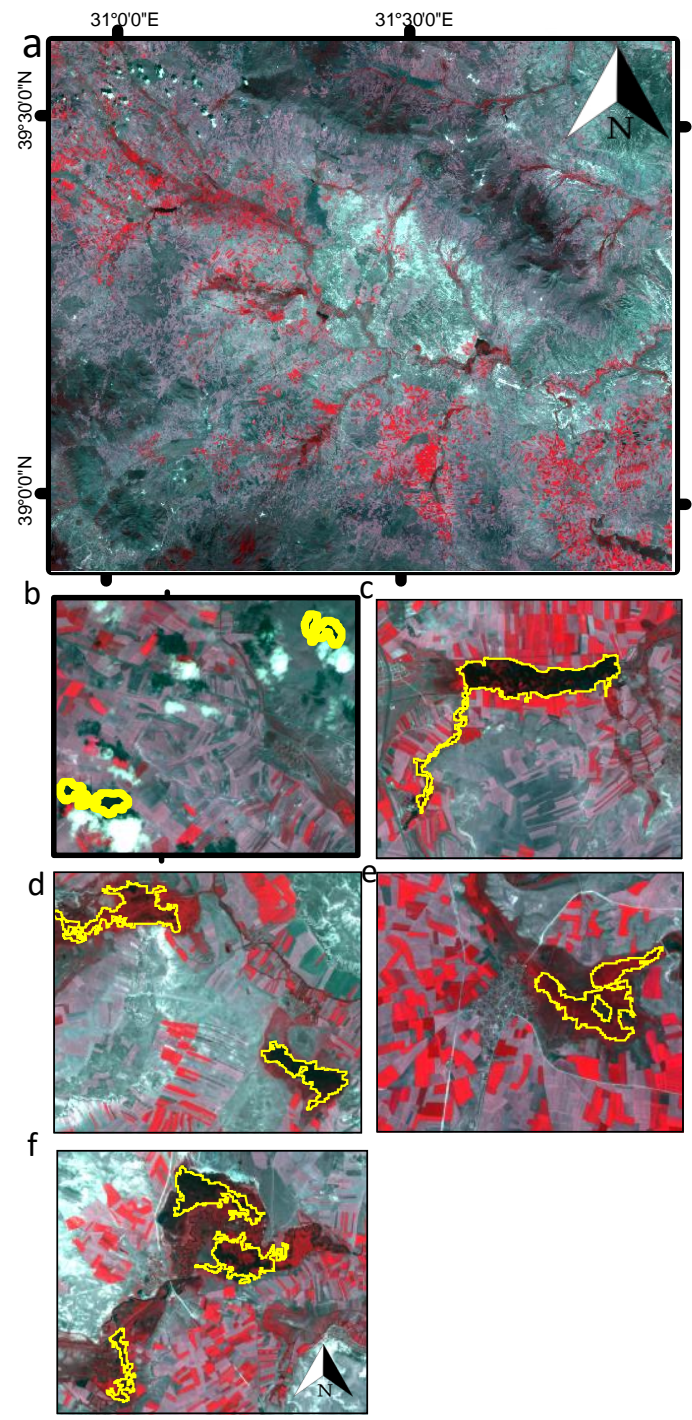

Figure 5. Object-based classification results within the a) Sentinel-2 frame; b) Clouds mislead; c) Sakarbasi wetland; d) Balikdami wetland; e) Kucukhasan wetland; f) Candir and Ortakoy wetlands. 


\subsection{Proposed Method}

Since none of the mentioned methods were successful in extracting the wetlands boundaries and the wetlands contents, in this paper we propose using of object-based classification and index-based classification as an alternative for monitoring and mapping wetlands. Firstly, we propose extraction of the boundaries using object-based classification based on a layer thresholds, and then using the NDVI and NDWI for calculating the fully vegetated, mixed, and water areas within the previously extracted boundaries (Figure 6).

The results from the NDVI analysis showed that on 31 July 2016 , the area of the Cifteler Sakarbasi springs was 2,238,900 m2. Detailed results are given in Table 2 and Figure 7.

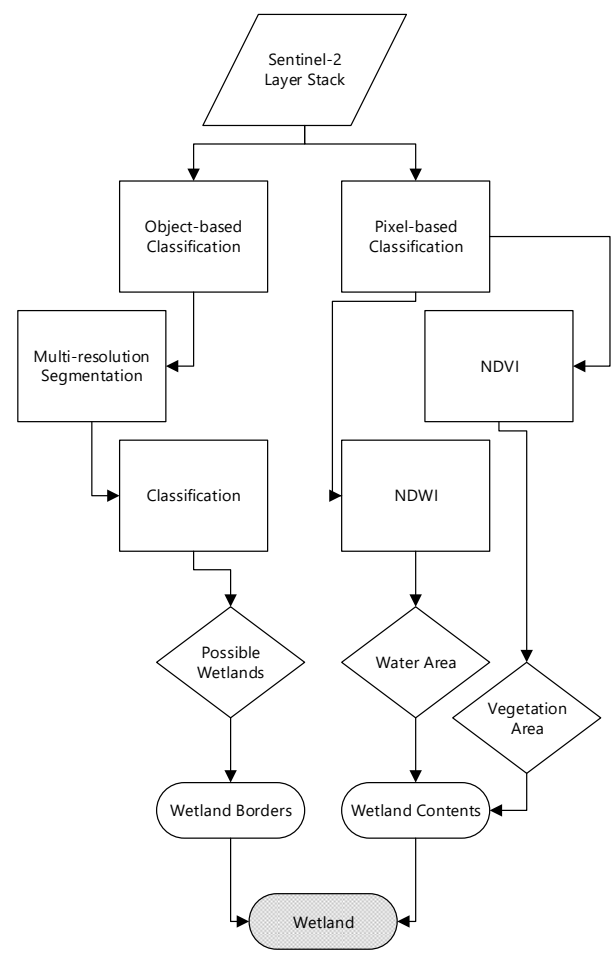

Figure 6 . Workflow of the new proposed method

\begin{tabular}{llll}
\hline NDVI & \multicolumn{3}{l}{ NDWI } \\
\hline Class & $\mathrm{m}^{2}$ & Class & $\mathrm{m}^{2}$ \\
\hline Soil & 100 & & \\
Non-vege & 14600 & Other & 1943800 \\
Mixture & 357200 & Mixture & 201700 \\
Vegetation & 1867000 & Open Water & 93400 \\
\hline Total & 2238900 & & 2238900 \\
\hline
\end{tabular}

Table 2. NDVI and NDWI results

From Figure 7 it can be clearly seen that with the results from the object-based and index-based classification it is possible to distinguish the wetlands and their contents from the other land covers.
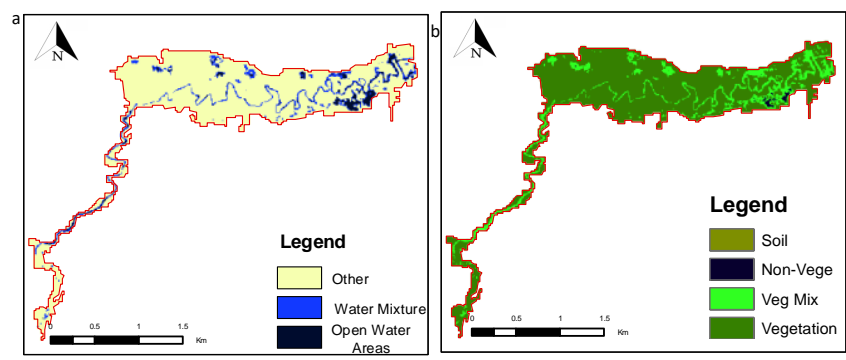

Figure 7. Object-based and index-based classification results

\subsection{Accuracy Assessment}

The accuracy assessment for the all of the used methods has been made by comparing the results with high-resolution images from Google Earth (Figure 8). Additionally, random points over Cifteler, Sakarbasi springs were used for the kappa value. Two hundred random points were used with a minimum allowed distance of $10 \mathrm{~m}$ to avoid random points on the same pixel. For the accuracy assessment, four classes have been separated within the study area, vegetated area, mixtures of soil and vegetation, open water bodies and mixtures of water and vegetation. The results from the accuracy assessment are presented in Table 3.
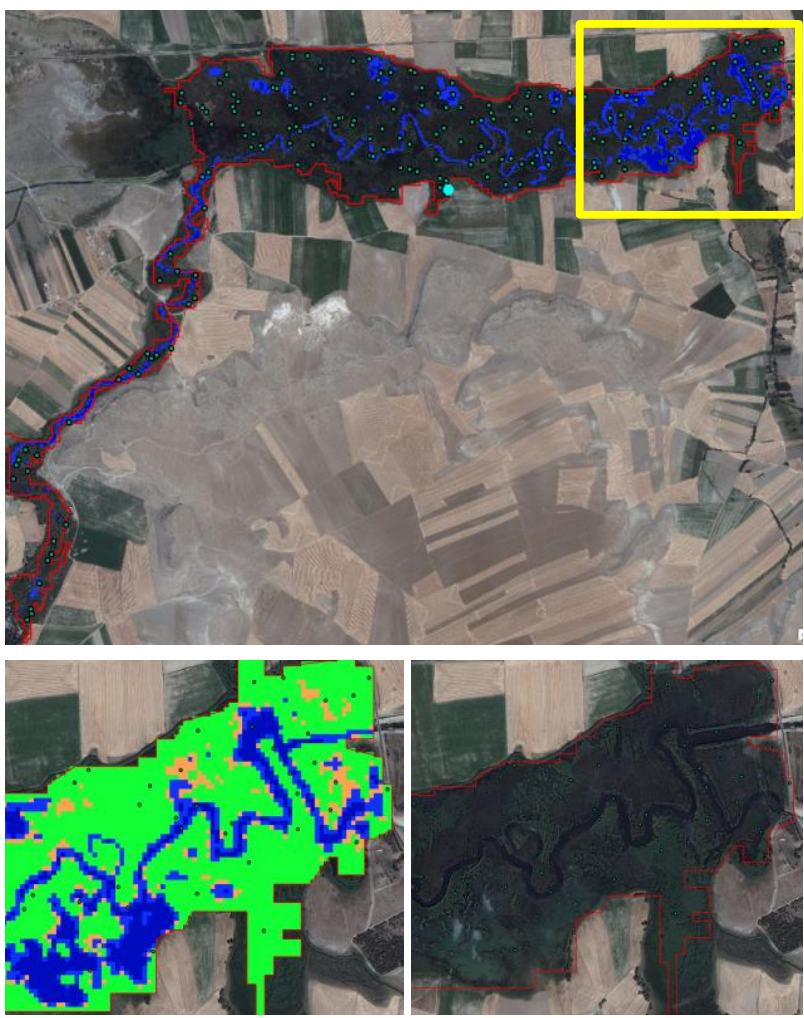

Figure 8. Accuracy assessment; comparison to the results with high-resolution image.

\begin{tabular}{cccc}
\hline $\begin{array}{c}\text { Overall } \\
\text { Accuracy }\end{array}$ & $\begin{array}{c}\text { Users } \\
\text { Accuracy }\end{array}$ & $\begin{array}{c}\text { Producer } \\
\text { Accuracy }\end{array}$ & Kappa \\
\hline $99 \%$ & $89.50 \%$ & $90.50 \%$ & 0.95 \\
\hline
\end{tabular}

Table 3. Accuracy Assessments Results 


\section{DISCUSSION}

Although different methods have been used for mapping wetlands, using remote sensing data from satellite images, due to the medium spatial resolution of the Landsat legacy, ASTER, or other satellites, separating wetlands from the other land cover has been hard without using additional data, as field measurements, Digital Elevation Models, LIDAR, etc. (Tiner, et al., 2015). In this paper, three different approaches have been used for mapping and monitoring wetlands over Sentinel-2 data with $10 \mathrm{~m}$ spatial resolution and three vegetation red edge indexes with $20 \mathrm{~m}$, resampled to $10 \mathrm{~m}$. While the unsupervised and supervised classification gave good results about the wetlands location with some misleads from dark areas such as forests, object-based classification gave better results about the location and boundaries of the wetlands. However, none of the methods gave information about the contents of the wetland areas. Using the index based classifications, we were able to extract the amount of vegetation, water, and mixture areas, but not and the boundaries of the wetlands.

In this paper, we propose using of both object-based and index based classifications for successful mapping and monitoring of wetlands. Using this method, within the Sentinel-2 frame five potential wetland areas were found. From the image, it was clear that one of the potential places is misled from cloud shadows. The other areas were confirmed using high-resolution imagery from Google Earth. The accuracy assessment made for the used method gave kappa value of 0.95 . It has been concluded that the proposed method is suitable for mapping and monitoring wetland area from Sentinel-2 satellite images with no additional data.

\section{ACKNOWLEDGEMENTS}

This study was supported by Anadolu University Scientific Research Projects Commission under the grant no: 1705F121.

\section{REFERENCES}

Butera, M. K. (1983). Remote sensing of wetlands. IEEE Transactions on Geoscience and Remote Sensing(3), 383-392.

Civco, D., Hurd, J., Prisloe, S., \& Gilmore, M. (2006). Characterization of coastal wetland systems using multiple remote sensing data types and analytical techniques. Paper presented at the IEEE Int. Conf. Geosci. Remote Sens. Symp. 2006 (IGARSS 2006).

Czajkowski, K., Torbick, N., \& Lawrence, P. (2007). Application And Assessment Of A Giscience Model For Jurisdictional Wetlands Identification In Northwestern Ohio Wetland and Water Resource Modeling and Assessment: A Watershed Perspective (pp. 2-12): CRC Press.

D'Odorico, P., Gonsamo, A., Damm, A., \& Schaepman, M. E. (2013). Experimental Evaluation of Sentinel-2 Spectral Response Functions for NDVI Time-Series Continuity. Ieee Transactions on Geoscience and Remote Sensing, 51(3), 1336-1348.

Dong, Z. Y., Wang, Z. M., Liu, D. W., Song, K. S., Li, L., Jia, M. M., et al. (2014). Mapping Wetland Areas Using LandsatDerived NDVI and LSWI: A Case Study of West Songnen Plain, Northeast China. Journal of the Indian Society of Remote Sensing, 42(3), 569-576.
Drusch, M., Del Bello, U., Carlier, S., Colin, O., Fernandez, V., Gascon, F., et al. (2012). Sentinel-2: ESA's optical highresolution mission for GMES operational services. Remote Sensing of Environment, 120, 25-36.

Dvorett, D., Davis, C., \& Papes, M. (2016). Mapping and Hydrologic Attribution of Temporary Wetlands Using Recurrent Landsat Imagery. Wetlands, 36(3), 431-443.

Ekercin, S., \& Ormeci, C. (2010). Evaluating climate change effects on water and salt resources in Salt Lake, Turkey using multitemporal SPOT imagery. Environmental Monitoring and Assessment, 163(1-4), 361-368.

Emiroğlu, O. (2011). Alien fish species in upper Sakarya River and their distribution. African Journal of Biotechnology, 10(73), 16674-16681.

Feyisa, G. L., Meilby, H., Fensholt, R., \& Proud, S. R. (2014). Automated Water Extraction Index: A new technique for surface water mapping using Landsat imagery. Remote Sensing of Environment, 140, 23-35.

Gao, B. C. (1996). NDWI - A normalized difference water index for remote sensing of vegetation liquid water from space. Remote Sensing of Environment, 58(3), 257-266.

Gobron, N., Pinty, B., Verstraete, M. M., \& Widlowski, J.-L. (2000). Advanced vegetation indices optimized for up-coming sensors: Design, performance, and applications. IEEE Transactions on Geoscience and Remote Sensing, 38(6), 24892505.

Gordana Kaplan, U. A., Zehra Y Avdan, Nalan D Yildiz. (2016). Drought Monitoring Using Landsat Satellite Images (Case Study Aksehir Lake). [Conference Paper].

Güner, F., \& Güner, I. (2002). Determination of hydrogeology of the karstic springs of Sakarbasi by using hydrochemistry and environmental isotope techniques.

Huang, C. Q., Peng, Y., Lang, M. G., Yeo, I. Y., \& McCarty, G. (2014). Wetland inundation mapping and change monitoring using Landsat and airborne LiDAR data. Remote Sensing of Environment, 141, 231-242.

Huete, A., Liu, H., Batchily, K. v., \& Van Leeuwen, W. (1997). A comparison of vegetation indices over a global set of TM images for EOS-MODIS. Remote sensing of environment, 59(3), 440-451.

Jensen, J., \& Christensen, E. (1986). Solid and hazardous waste disposal site selection using digital geographic information system techniques. Science of the total environment, 56, 265276.

Ji, W. (2007). Wetland and water resource modeling and assessment: a watershed perspective: CRC Press.

Kaufman, Y. J., \& Tanre, D. (1992). Atmospherically resistant vegetation index (ARVI) for EOS-MODIS. IEEE transactions on Geoscience and Remote Sensing, 30(2), 261-270.

Kayastha, N., Thomas, V., Galbraith, J., \& Banskota, A. (2012). Monitoring Wetland Change Using Inter-Annual Landsat TimeSeries Data. Wetlands, 32(6), 1149-1162. 
Li, J. H., \& Chen, W. J. (2005). A rule-based method for mapping Canada's wetlands using optical, radar and DEM data. International Journal of Remote Sensing, 26(22), 5051-5069.

Malenovský, Z., Rott, H., Cihlar, J., Schaepman, M. E., GarcíaSantos, G., Fernandes, R., et al. (2012). Sentinels for science: Potential of Sentinel-1,-2, and-3 missions for scientific observations of ocean, cryosphere, and land. Remote Sensing of environment, 120, 91-101.

McFeeters, S. K. (1996). The use of the normalized difference water index (NDWI) in the delineation of open water features. International Journal of Remote Sensing, 17(7), 1425-1432.

Melack, J. M., \& Hess, L. L. (2010). Remote sensing of the distribution and extent of wetlands in the Amazon basin Amazonian floodplain forests (pp. 43-59): Springer.

Mitsch, W. J. (2009). Wetland ecosystems: John Wiley \& Sons.

Mitsch, W. J., \& Gosselink, J. G. (2015). Wetlands. Wetlands, 155-204.

Morandeira, N. S., Grings, F., Facchinetti, C., \& Kandus, P. (2016). Mapping Plant Functional Types in Floodplain Wetlands: An Analysis of C-Band Polarimetric SAR Data from RADARSAT-2. Remote Sensing, 8(3).

Moser, L., Schmitt, A., Wendleder, A., \& Roth, A. (2016). Monitoring of the Lac Bam Wetland Extent Using DualPolarized X-Band SAR Data. Remote Sensing, 8(4).

Ozgur, E. (2015). İç Sularda Üretim Denemesi Yapılan Alternatif Balık Türlerinin Doğal İhtiyofaunaya Olası Etkileri: Çifteler (Eskişehir) Sakaryabaşı Örneği.

Pinty, B., \& Verstraete, M. (1992). GEMI: a non-linear index to monitor global vegetation from satellites. Plant ecology, 101(1), 15-20.

Ramsey, E. W., \& Laine, S. C. (1997). Comparison of landsat thematic mapper and high resolution photography to identify change in complex coastal wetlands. Journal of Coastal Research, 13(2), 281-292

Sentinel, E. Delivers First Images. Available onlin e: http://www. esa. int/Our_Activities/Observing the_Earth/Copernicus/Sentinel-2/Sentinel-

2_delivers_first_images (accessed on 7 January 2016).

Trishchenko, A. P., Cihlar, J., \& Li, Z. (2002). Effects of spectral response function on surface reflectance and NDVI measured with moderate resolution satellite sensors. Remote Sensing of Environment, 81(1), 1-18.

Ustin, S. (2004). vol. 4: Remote sensing for natural resource management and environmental monitoring.

Vakfi, T. C. S. (1989). Wetlands in Turkey (Turkiye`nin Sulak Alanlari): Onder Matbaa.

White, L., Brisco, B., Dabboor, M., Schmitt, A., \& Pratt, A. (2015). A Collection of SAR Methodologies for Monitoring Wetlands. Remote Sensing, 7(6), 7615-7645.

WWAP, U. (2003). UN World Water Development Report: Water for People. Water for Life.
Zomer, R. J., Trabucco, A., \& Ustin, S. (2009). Building spectral libraries for wetlands land cover classification and hyperspectral remote sensing. Journal of Environmental Management, 90(7), 2170-2177. 